J. Clin. Chem. Clin. Biochem.

Vol. 28,1990 , pp. $419-421$

C 1990 Walter de Gruyter \& Co. Berlin · New York

\title{
The Clinical Evaluation of Cobalamin Deficiency by Determination of Methylmalonic Acia in Serum or Urine is not Invalidated by the Presence of Heterozygous Methylmalonic-Acidaemia ${ }^{1}$ )
}

\author{
By K. Rasmussen ${ }^{1}$ and E. Nathan ${ }^{2}$ \\ ${ }^{1}$ Klinisk-kemisk afdeling, Aarhus Kommunehospital, Aarhus, Danmark \\ ${ }^{2}$ Borneafdelingen, Aarhus Kommunehospital, Aarhus, Danmark
}

(Received January 31/March 22, 1990)

\begin{abstract}
Summary: It is well established that accumulation of methylmalonic acid may provide an early clue to the existence of tissue cobalamin (vitamin $\mathrm{B}_{12}$ ) deficiency. To verify whether methylmalonic acid accumulates in adult heterozygotes for inherited methylmalonic-acidaemia and thereby gives "false" positive test results for cobalamin deficiency, we measured the concentration of methylmalonic acid in serum and its urinary excretion in six parents of three children with severe methylmalonic-acidaemia. We found levels of methylmalonic acid similar to those in normal subjects. In serum, the concentrations of methylmalonic acid ranged from 0.12 to $0.39 \mu \mathrm{mol} / 1$ (reference range: $0.05-0.44 \mu \mathrm{mol} / \mathrm{l}$ ). In urine, the values ranged from 1.18 to $2.48 \mathrm{mmol}$ per mol of creatinine (reference range: $0.58-3.56$ ). We conclude that the $2 \%$ of carriers of inherited methylmalonicacidaemia in the general population do not invalidate the usefulness of measurement of methylmalonic acid in serum or urine for the clinical evaluation of cobalamin deficiency.
\end{abstract}

\section{Introduction}

Determination of methylmalonic acid in serum or urine for evaluating cobalamin deficiency has recently aroused interest in clinical chemistry, especially as an important diagnostic procedure in patients with neurologic disorders with few or no haematological abnormalities, or normal or only slightly depressed serum cobalamin concentrations $(1-3)$. $L(\mathrm{R})$-methylmalonyl-CoA is a normal intermediate in the biochemical pathway from propionyl-CoA to succinylCoA. Precursors of propionyl-CoA include isoleucine, valine, threonine, methionine, cholesterol, and oddcarbon-number fatty acids. In children with inherited disorders of cobalamin metabolism or enzyme defects in the complex, metabolic conversion of methylmalonic acid (the various inherited methylmalonic aci-

1) This work was supported by a grant from:

The Institute of Experimental Clinical Research, Aarhus Universitet, DK-8000 Aarhus C., Danmark. daemias), methylmalonic acid is found in serum and urine in large quantities. In adults, methylmalonic acid accumulates when the conversion of $L(\mathrm{R})$-methylmalonyl-CoA to succinyl-CoA by methylmalonylCoA mutase ${ }^{2}$ ), mediated by $5^{\prime}$-deoxyadenosylcobalamin, becomes impaired due to aquired cobalamin deficiency. An increased concentration of methylmalonic acid in serum and its excessive urinary excretion are believed to be direct measures of tissue stores of cobalamin (4) and thus provide the first indication of functional cobalamin deficiency $(3,5)$.

Recently, Lindenbaum et al. (3) reported that among 30 patients with neuropsychiatric disorders with no haematological abnormalities, and with initial elevations of serum methylmalonic acid, the level fell mark-

\footnotetext{
2) Methylmalonyl-CoA mutase (formerly isomerase) EC 5.4.99.2
} 
edly in all but 2 after treatment with cobalamin. This finding prompted us to examine the possibility that such subjects could be carriers of methylmalonicacidaemia (6). The combined incidence of these autosomal recessive disorders is about one per 10000 live births. This means that the frequency of heterozygotes for these traits in the normal population is approximately $2 \%$. However, there are no data for serum methylmalonic acid in the heterozygotes.

We undertook the present study to explore the possibility that methylmalonic acid accumulates in heterozygotes for methylmalonic-acidaemia, thereby invalidating the usefulness of the determination of methylmalonic acid in serum or urine for the clinical evaluation of cobalamin deficiency.

\section{Materials and Methods}

Freshly collected random urine samples and serum specimens were obtained from six parents, aged 38 to 45 years, of three children with severe methylmalonic-acidaemia (63.4-287 $\mu \mathrm{mol} / \mathrm{l})$ and stored at $-20^{\circ} \mathrm{C}$ until they could be analysed.

Methylmalonic acid in serum and urine was assayed using stable-isotope-dilution with solid-phase extraction of the samples; the dicyclohexyl derivatives were determined by a gas chromatographic-mass spectrometric procedure with the mass spectrometer in the selected-ion monitoring mode, as previously described in detail (7). All specimens were assayed in duplicate. Between-day imprecision of the method, determined twice during routine analyses for 20 days, is $0.025 \mu \mathrm{mol} / 1$ (SD) at a concentration in serum of $0.32 \mu \mathrm{mol} / 1(\mathrm{CV}=7.9 \%)$. For urine, the between-day imprecision is 0.08 at a concentration of 1.20 mmol per mol of creatinine $(\mathrm{CV}=6.7 \%)$. The concentration of methylmalonic acid in urine specimens from 20 healthy, adult hospital personnel, aged $22-56$ years, ranged from 0.58 to 3.56 mmol per mol of creatinine (mean $=1.68$ ). No age- or sexrelated differences were apparent (7). In 58 throughly investigated non-cobalamin-deficient healthy subjects, aged 40-68 years, we most recently found a range of $0.05-0.44 \mu \mathrm{mol} / 1$ (mean $=0.21, \mathrm{SD}=0.094)$. A $\chi^{2}$ goodness-of-fit test did not prove any deviation from the normal distribution $(0.90>\mathrm{P}$ $>0.80$ ), and no age- or sex-related differences could be demonstrated (data to be published elsewhere).

Creatinine was determined by the Technicon automated alkaline picrate method (8). Serum cobalamin concentrations were assayed using a RIA method utilizing hog intrinsic factor (9).

\section{Results}

As shown in table 1, in heterozygosity for methylmalonic-acidaemia, the concentrations of methylmalonic acid were similar to those in normal subjects. In serum, concentrations of methylmalonic acid ranged from 0.12 to $0.39 \mu \mathrm{mol} / 1$ (mean $=0.23$ ). In urine, the values ranges from 1.18 to $2.48 \mathrm{mmol}$ per mol of creatinine $($ mean $=1.79)$. As expected, serum cobalamin concentrations were normal (390-770 pmol/1; reference range: $200-800 \mathrm{pmol} / \mathrm{l})$.
Tab. 1. Concentrations in serum and urinary excretion of methylmalonic acid in six heterozygotes, parents of 3 children suffering from severe methylmalonic-acidaemia

\begin{tabular}{|c|c|c|c|}
\hline \multirow[t]{2}{*}{ Sex } & \multirow{2}{*}{$\begin{array}{l}\text { Age } \\
\text { (a) }\end{array}$} & \multicolumn{2}{|c|}{ Methylmalonic acid } \\
\hline & & $\begin{array}{l}\text { Serum } \\
(\mu \mathrm{mol} / \mathrm{l})\end{array}$ & $\begin{array}{l}\text { Urine } \\
\text { (mmol/mol creatinine) }\end{array}$ \\
\hline q & 38 & 0.12 & 1.18 \\
\hline o & 41 & 0.14 & 1.42 \\
\hline q & 45 & 0.21 & 1.92 \\
\hline $\overrightarrow{0}$ & 42 & 0.36 & 1.69 \\
\hline$q$ & 39 & 0.39 & 2.07 \\
\hline$\widehat{0}$ & 42 & 0.14 & 2.48 \\
\hline \multicolumn{4}{|c|}{ Healthy controls } \\
\hline \multirow{2}{*}{\multicolumn{2}{|c|}{$\begin{array}{l}\text { range } \\
\text { mean }\end{array}$}} & $0.05-0.44$ & $0.58-3.56$ \\
\hline & & 0.21 & 1.68 \\
\hline \multicolumn{2}{|c|}{ n } & 58 & 20 \\
\hline
\end{tabular}

\section{Discussion}

Acquired cobalamin deficiency is a continuum with anaemia and macrocytosis only in the final stage (10). Currently, serum cobalamin is essentially the only diagnostic parameter in clinical chemistry generally available for determining whether a patient is cobalamin deficient. It is therefore still widely used, both for clinical and research purposes, as in index of tissue cobalamin deficiency. However, serum cobalamin does not necessarily reflect the cobalamin status of the body. In cobalamin deficiency, serum cobalamin levels may be normal or high, and furthermore, low levels of cobalamin in serum do not prove deficiency. The limitations in using only the serum cobalamin concentration to detect cobalamin deficiency are widely recognized $(11-14)$, the need for an ancillary diagnostic test in patients with low or low-normal serum cobalamin has been emphasized, and testing for methylmalonic acid has been recommended $(1-3$, $15-18)$. Because of the considerably higher concentrations of methylmalonic acid in urine as compared with serum, most studies have dealt with its measurement in the former. However, patients with early evidence of cobalamin deficiency may be best differentiated from normal subjects by measurement of serum methylmalonic acid (19).

Now that the analysis of serum methylmalonic acid is becoming increasingly used in clinical laboratories, it is necessary to study the effect of various pathological conditions. As mentioned, methylmalonic acid accumulates in at least two conditions, i. e. in patients with acquired cobalamin deficiency, and in children with inherited abnormalities in the metabolic pathway for methylmalonic acid. The relevant metabolites accumulate in heterozygotes for some inherited disorders. The present study, however, gives no evidence 
of impaired methylmalonic acid metabolism in heterozygotes for methylmalonic-acidaemia. Therefore, the $2 \%$ of heterozygotes in the general population do not invalidate the usefulness of the measurement of methylmalonic acid in serum or urine. Our results further show that normal levels of methylmalonic acid do not exclude the heterozygous state, and determination of serum methylmalonic acid is not a tool for detection of carriers in families with a history of methylmalonicacidaemia.

\section{References}

1. Stabler, S. P., Marcell, P. D., Podell, E. R., Allen, R. H. \& Lindenbaum, J. (1986) Assay of methylmalonic acid in the serum of patients with cobalamin deficiency using capillary gas chromatography-mass spectrometry. J. Clin. Invest. 77, $1606-1612$.

2. Lindenbaum, J., Savage, D. G., Stabler, S. P. \& Allen, R. H. (1988) Cobalamin deficiency and neuropsychiatric disorders [Letter]. N. Engl. J. Med. 319, 1734.

3. Lindenbaum, J., Healton, E. B., Savage, D. G., Brust, J. C. M., Garrett, T. J., Podell, E. R., Marcell, P. D., Stabler, S. P. \& Allen, R. H. (1988) Neuropsychiatric disorders caused by cobalamin deficiency in the absence of anemia or macrocytosis. N. Engl. J. Med. 318, 1720-1728.

4. Higginbottom, M. C., Sweetman, L. \& Nyhan, W. L. (1978) A syndrome of methylmalonic aciduria, homocystinuria, megaloblastic anemia: neurologic abnormalities in a vita$\min \mathrm{B}_{12}$-deficient breast-fed infant of a strict vegetarian. $\mathrm{N}$. Engl. J. Med. 299, 317-323.

5. Norman, E. J., Martelo, O. J. \& Denton, M. D. (1982) Cobalamin (vitamin $\mathrm{B}_{12}$ ) deficiency detection by urinary methylmalonic acid quantitation. Blood 59, 1128-1131.

6. Rasmussen, K. \& Nathan, E. (1989) Carriers of methylmalonic-acidemia have normal concentrations of methylmalonic acid in serum and urine [Abstract]. Proceedings, 27th SSIEM Annual Symposium, p. 84, Munich.

7. Rasmussen, K. (1989) Solid-phase sample extraction for rapid determination of methylmalonic acid in serum and urine by a stable-isotope-dilution method. Clin. Chem. 35 , $260-264$

8. Di Giorgio, J. (1974) Nonprotein nitrogenous constituents. In: Clinical Chemistry, Principles and Technics, 2nd edn. (Henry, R. J., Cannon, D. C. \& Winkelman, J. W., eds.) pp. 503-563, Harper and Row Publishers, Hagerstown.

9. Mortensen, E. (1972) Negative interference by residual proteins in the supernatant fluid used in radioisotopic assay of serum vitamin $\mathrm{B}_{12}$. Clin. Chem. 18, 895-900.

10. Herbert, V. (1988) Don't ignore low serum cobalamin (vitamin $\mathrm{B}_{12}$ ) levels [Editorial] Arch. Intern. Med. 148, 17051707.

11. Corcino, J. J., Zalusky, R., Greenberg, M. \& Herbert, V. (1971) Coexistence of pernicious anaemia and chronic myeloid leukemia: an experiment of nature involving vitamin $\mathrm{B}_{12}$ metabolism. Br. J. Haematol. 20, 511-520.

12. Norman, E. J., Logan, D. \& Terrell, P. (1986) Falsely high serum $\mathrm{B}_{12}$ levels [Letter]. Am. J. Clin. Pathol. 86, 692.

13. Carmel, R. (1988) Pernicious anemia. The expected findings of very low serum cobalamin levels, anemia, and macrocytosis are often lacking. Arch. Intern. Med. 148, 17121714.

14. Herbert, V. (1988) Cobalamin deficiency and neuropsychiatric disorders [Letter]. N. Engl. J. Med. 319, 1733.

15. Matchar, D. B., Feussner, J. R., Millington, D. S., Wilkinson, R. H., Watson, D. J. \& Gale, D. (1987) Isotopedilution assay for urinary methylmalonic acid in the diagnosis of vitamin $\mathrm{B}_{12}$ deficiency. Ann. Intern. Med. 106, $707-710$.

16. Norman, E. J. (1987) New urinary methylmalonic acid test is a sensitive indicator of cobalamin (vitamin $B_{12}$ ) deficiency: a solution for a major unrecognized medical problem [Letter]. J. Lab. Clin. Med. 110, 369.

17. Norman, E. J., Denton, M. D., Martelo, O. J. \& Flessa, H. C. (1988) Cobalamin deficiency and neuropsychiatric disorders [Letter]. N. Engl. J. Med. 319, 1733.

18. Rasmussen, K., Moelby, L. \& Jensen, M. K. (1989) Studies on methylmalonic acid in humans. II. Relationship between concentrations in serum and urinary excretion, and the correlation between serum cobalamin and accumulation of methylmalonic acid. Clin. Chem. 35, 2277-2280.

19. Rasmussen, K. (1989) Studies on methylmalonic acid in humans. I. Concentrations in serum and urinary excretion in normal subjects after feeding and during fasting, and after loading with protein, fat, sugar, isoleucine, and valine Clin. Chem. 35, 2271-2276.

Dr Karsten Rasmussen

Research Laboratory for Metabolic Disorders

University Department of Clinical Chemistry

Aarhus Kommunehospital

DK-8000 Aarhus C 
